\title{
A PAIXÃO SEGUNDO O BÚFALO: O CORPO MELANCÓLICO EM CLARICE LISPECTOR
}

\section{PASSION ACCORDING THE BUFFALO: THE MELANCHOLIC BODY IN CLARICE LISPECTOR}

\section{Amanda Ramalho de Freitas Brito}

\begin{abstract}
RESUMO: As paixões participam e impulsionam a experiência humana, pois como sugeriu Lebrun (2009) em O conceito de paixão, nos induz a realizar a ação modificadora. A ação movida pelas paixões pode criar a presença eminente do prazer em uma situação conciliadora doada pelo encontro, ou revelar uma dor latente no processo disfórico do encontro. Nessa perspectiva apresenta-se a melancolia das paixões, centrada na relação da perda ideal do objeto de amor. Nesse sentido, o presente artigo busca pensar como a melancolia está presente no percurso da paixão que participa da construção da personagem em "O búfalo", de Clarice Lispector. Investigando os seus sentidos ambivalentes e complementares (passividade e ação; amor e ódio) como norteadores da melancolia no conto e da significação dos estados instintivos do "eu". Para ancorar a pesquisa busquei um percurso de análise centrado na psicanálise de base freudiana, destacando os ensaios: Luto e Melancolia e o Eu e o ld.
\end{abstract}

PALAVRAS-CHAVE: Paixão. Melancolia. Literatura. Psicanálise. Clarice Lispector.

ABSTRACT: Passions participate and boost the human experience, because as Lebrun (2009) suggested in $O$ conceito de paixão (The concept of passion), it induces us to carry out the modifying action. Passion-driven action can create the eminent presence of pleasure in a conciliatory situation bestowed by the encounter, or reveal a latent pain in the dysphoric process of encounter. In this perspective the melancholy of the passions is centered in the relation of the ideal loss of the object of love. In this sense, the present article tries to think how the melancholy is present in the course of the passion that participates in the construction of the character in "O búfalo" ("The buffalo"), by Clarice Lispector. Investigating their ambivalent and complementary senses (passivity and action, love and hate) as guiding the melancholy in the tale and the significance of the instinctive states of the "l". In order to anchor the research, I sought a course of analysis centered on Freudian psychoanalysis, highlighting the essays: "Luto e Melancolia" ("Mourning and Melancholia") and "Eu e o Id" ("The Ego and the Id").

KEYWORDS: Passion. Melancholy. Literature. Psychoanalysis. Clarice Lispector.

Submetido em: 29 nov. 2018.

Aprovado em: 16 out. 2018

Universidade Estadual de Alagoas e Universidade Federal da Paraíba. E-mail: amandaramalhobrito@gmail.com. 


\title{
A melancolia das paixões: o caso do búfalo
}

\author{
O pássaro é livre \\ na prisão do ar. \\ O espírito é livre \\ na prisão do corpo. \\ Mas livre, bem livre, \\ é mesmo estar morto. \\ Carlos Drummond de Andrade
}

Para Lebrun (2009), a paixão tem o sentido passivo de tendência: uma tendência modificadora daquilo que chamo de estado de euforia ou disforia do "Eu", ou do prazer ou da dor. Essa tendência é compreendida como passiva porque depende do outro para estabelecer uma estrutura psíquica de prazer ou desprazer. Assim, "a paixão é sempre provocada pela presença ou imagem de algo que me leva a reagir, geralmente de improviso. Ela é então o sinal de que eu vivo na dependência permanente do Outro." (LEBRUN, 2009, p. 13).

Em "O búfalo", conto de Clarice Lispector, inserido em Laços de Família (1960), a ação que move a personagem é a paixão disfórica, o pathos da mulher rejeitada, que procura o sentido da existência na projeção de um ódio representado no outro - o animal enjaulado. A jaula aponta simbolicamente para a prisão psíquica do "eu" no eixo das tensões emotivas entre amor e ódio, ambivalência ressaltada pela comunhão dos bichos e pela demarcação temporal da exaltação da vida primaveril, mesmo na situação de um espaço físico fechado: "mas era primavera. Até o leão lambeu a testa glabra da leoa." (LISPECTOR, 2016, p. 248). A conjunção "mas" reitera a insinuosa ambiguidade da existência pela insinuosa criação das palavras, que em Clarice parece funcionar como um dispositivo poético de interiorização da experiência. O ponto de tensão entre o amor e ódio é o liame da melancolia no conto, pois estabelece a intriga narrativa. Essa construção conflituosa na melancolia em decorrência da perda do objeto de amor pode ser entendida por Freud (2010), quando nos diz que:

Mas a melancolia, como vimos, tem algo mais no conteúdo que o luto normal. Nela a relação com o objeto não é simples, sendo complicada pelo conflito da ambivalência. Essa é ou constitucional, isto é, própria de todo vínculo amoroso desse $\mathrm{Eu}$, ou nasce das vivências ocasionadas pela ameaça da perda do objeto. Por isso a melancolia, 
no tocante aos motivos, pode ultrapassar bastante o luto, que via de regra é desencadeado somente pela perda real, a morte do objeto. Portanto, na melancolia travam-se inúmeras batalhas em torno do objeto, nas quais ódio e amor lutam entre si, uma para desligar a libido do objeto, o outro, para manter essa posição da libido contra o ataque. (FREUD, 2010, p. 191).

Em "O búfalo", a oposição evidencia uma tentativa de substituir Eros por Tânatos, uma vez que a destruição da consciência do estado de amor aplacaria o pathos, o destino fatídico que havia repelido a mulher da comunhão a dois. $O$ ódio seria a representação da morte, como psicanaliticamente o é: "o ódio é um representante do instinto de morte (...). Supusemos que há um instinto de morte, cuja tarefa é reconduzir os organismos viventes ao estado inanimado." (FREUD, 2011, p. 50). Por isso, percebemos no desfecho do conto a imagem descrita de uma morte metafórica centrada na vertigem do corpo esmaecido quando a mulher, finalmente, no eixo de encontro com o búfalo, identifica o objeto de representação do ódio: "presa, enquanto escorregava enfeitiçada ao longo das grades. Em tão lenta vertigem que antes do corpo baquear macio a mulher viu 0 céu inteiro e um búfalo." (LISPECTOR, 2016, p. 257).

Essa perda da consciência representada comumente na literatura pelo sonho, pelo sono ou pelo esquecimento coloca o personagem em um mundo situado numa realidade paralela, criando um efeito de transformação das vivências, como se pudesse adentrar-se no espaço do inconsciente para dar forma à imaginação e às lacunas do passado, como em Macário, de Álvares de Azevedo e A divina comédia, de Dante Alighieri. No entanto, no texto de Lispector, a perda de consciência ratifica o estado de completude do ato da procura da sua "missão mortal": a pulsão de morte encontrada no ato da indiferença pelo único animal incompassível a sua construção de amor.

A paixão segundo o búfalo é o objeto de revelação da pulsão destruidora e da pulsão erótica: "Eu te amo, disse ela então com ódio para o homem cujo grande crime impunível era o de não querê-la. Eu te odeio, disse implorando amor ao búfalo". (LISPECTOR, 2016, p. 256). O próprio Freud em As duas espécies de instintos (1923), nos mostra como o ódio pode acompanhar e até se transformar em amor, instintos que se alimentam, tornando inconsciente a dolorosa trajetória da vida conjuntamente com o alargamento dela, numa espécie de explosão da mesma. Dessa maneira, a construção e a transformação 
psíquica do "eu" está entrelaçada passivamente ao outro, como reforça Nunes (1989) ao refletir sobre as personagens de Clarice Lispector:

\begin{abstract}
Sujeitas à roda de estados mutáveis que as encadeiam num fluxo e no refluxo imprevisíveis, as personagens de Clarice Lispector são mais pacientes do que agentes de uma experiência interior que não podem controlar, e onde nada há de permanente a não ser também a paixão da existência que também lhes é comum. (NUNES, 1989, p. 104).
\end{abstract}

A relação de dependência com o outro determina a natureza da paixão, e consequentemente a própria melancolia, gerada pelo desejo incompleto, já que o sujeito não alcança a sua plenitude ideal, como em meu corpus de análise: a personagem amando não consegue suprimir o desejo do ódio e odiando não consegue suprimir o desejo do amor. Desse modo, há nas paixões uma intrínseca melancolia, ancorada na busca ideal do objeto de amor, cujo sentido se desfaz pelo desejo insatisfeito pelo desencontro com o mesmo objeto de amor. "O desejo inconsciente, recalcado, mantém-se em estado de alerta, em busca de representação ou expressão através das formações do inconsciente." (EDLER, 2008, p. 77). Esse desejo recalcado expressa tanto a pulsão de vida como de morte representada no conto pelo búfalo, que em várias culturas representa a divindade da morte, como apontam Chevalier e Gheerbrant (1998), no Dicionário de símbolos. O búfalo seria o objeto idealizado do "eu".

Partindo da ideia psicanalista do "Ideal do Eu" ou "Super-eu" (Über-ich), discutida por Freud no ensaio O eu e o id (1923), somos guiados a entender a relação do "Eu" com o mundo a partir do estabelecimento de uma representação de desejos primitivos interrompidos pela consciência moral. Como diz Freud (2011, p. 45): "o que a biologia e as vicissitudes da espécie humana criaram e deixaram no ld é assumido pelo Eu, através da formação do ideal, e revivenciado nele individualmente". Nesse sentido, as experiências reprimidas ou os objetos perdidos são forjados pelo Super-eu, ou pela substituição de um investimento objetal por um objeto de identificação, caso que ressoa a própria natureza da melancolia. Por isso, a concepção de arte aristotélica nos diz que "o temperamento melancólico é um temperamento metafórico, propenso, pois, à criação". (SCLIAR, 2003, p. 70). Com efeito, trata-se de uma reflexão também sobre linguagem, sobre como nos inserimos simbolicamente no tecido da vida. 
Assim, há em "O búfalo" uma imersão do sujeito com o mundo por meio da transferência do sentimento subjetivo para o objeto de identificação - os animais do zoológico, em uma tentativa adjacente de superar a dor da rejeição. O drama da personagem inominada é também o drama da linguagem, pelo qual os signos remetem às tensões internas, como o espaço de desenvolvimento narrativo, o zoológico, apontando o estado de aprisionamento da personagem:

O quati curioso lhe fazendo uma pergunta como uma criança pergunta. E ela desviando os olhos, escondendo dele a sua missão mortal. A testa estava tão encostada às grades que por um instante lhe pareceu que ela estava enjaulada e que um quati livre a examinava. A jaula era sempre do lado onde ela estava. (LISPECTOR, 2016, p. 256).

No trecho selecionado, o narrador cria um ponto de vista que coloca a personagem como eixo de observação do "quati", e a partir de um close cinematográfico ${ }^{1}$ inverte a condição de isolamento dos personagens: mulher e animal, ressaltando por meio do espaço a psiquê da personagem. O vínculo estabelecido entre pessoa e animal retoma o sentido característico do signo zoológico (estudo dos animais), de origem grega, no século XVIII remetia ao espaço onde se estudava os animais.

Assim a mulher do conto procura, tal como Lóri, de Uma aprendizagem ou livro dos prazeres, um caminho de descoberta, aprendizagem, neste caso, não do amor, mas do ódio: "mas onde, onde encontrar o animal que lhe ensinasse a ter o seu próprio ódio.” (LISPECTOR, 2016, p. 253). No conto também se manifesta o zoológico como espaço onde a mulher se torna objeto de observação, tendo em vista a aproximação estabelecida entre ambos, ou seja, o espaço de enjaulamento dos animais é um nexo íntimo de projeções da própria personagem, que busca induzir através do jardim zoológico o ideal do Eu: "ela que fora ao jardim zoológico para adoecer." (LISPECTOR, 2016, p. 248).

Conforme nos faz pensar Bachelard (1978), o espaço que frequentamos não é apenas geográfico, mas um espaço vivido, poetizado, funcionando como

\footnotetext{
${ }^{1} \mathrm{O}$ close é um enquadramento doado pela câmera, um artificio (plano) narrativo do cinema para destacar, colocar em ênfase um objeto ou a parte de um corpo, com intuito de apontar uma significação psicológica do filme. De acordo com Martin (2003, p. 39), "é esse tipo de plano que constitui a primeira, e no fundo a mais válida, tentativa de cinema interior". No texto de Lispector, esse enquadramento doado pelas palavras também revela o estado psíquico da personagem: a prisão.
} 
extensão do Eu. Essa ideia está presente, por exemplo, quando a personagem procura ter a sua própria violência por meio da experiência eufórica na montanha russa: "Então foi sozinha ter a sua violência. (...). O banco ainda parado, a maquinaria da montanha-russa ainda parada. Separada de todos no seu banco parecia estar sentada numa igreja." (LISPECTOR, 2016, p. 250).

A imagem emblemática da igreja projeta o espaço de sozinhez ${ }^{2}$ da personagem, que numa atitude quase sagrada de devoção e fé procura encontrar o objeto de desejo - o seu par no mundo: "oh, Deus, quem será meu par neste mundo?" (LISPECTOR, 2016, p. 250). O discurso da mulher representa a polarização dos próprios sentimentos (amor e ódio), porque aparentemente o par procurado é o ódio, a indiferença do animal, objeto de identificação, mas o trecho aponta para o homem - o objeto de amor perdido ou não identificado. Dessa forma, a paixão reverbera a melancolia da personagem e a ambivalência do percurso narrativo da mesma, que encontra o objeto procurado, mas não soluciona o conflito interno: ama com ódio e odeia "implorando amor ao búfalo".

\section{Referências}

BACHELARD. Gaston. A poética do espaço. In: Os pensadores. Tradução: Joaquim José Moura Ramos. São Paulo: Abril Cultural, 1978.

CHEVALIER, Jean; GHEERBRANT, Alain. Dicionário de símbolos. Rio de Janeiro, José Olympio, 1998.

CORDÁS, T. Athanássios; EMILIO, M. Schumaker. História da melancolia. Porto Alegre: Artmed, 2017.

EDLER, Sandra. Luto e melancolia: à sombra do espetáculo. Rio de Janeiro: Civilização Brasileira, 2008.

FREUD, Sigmund. Luto e melancolia. In: FREUD, Sigmund. Obras completas, volume 12: introdução ao narcisismo, ensaios de metapsicologia e outros textos (1914-1916). Tradução: Paulo César de Souza. São Paulo: Companhia das Letras, 2010. p. 170-194.

\footnotetext{
2 Termo criado por Paulo Mendes Campos na crônica "Para Maria da Graça", inserida no livro $O$ amor acaba: crônicas líricas e existenciais.
} 
FREUD, Sigmund. Obras completas, volume 16: o eu e o id, autobiografia e outros textos (1923-1925). Tradução: Paulo César de Souza. São Paulo: Companhia das Letras, 2011.

LEBRUN, Gérard. O conceito de paixão. In: LEBRUN, Gérard. Os sentidos de paixão. São Paulo: Companhia das Letras, 2009.

LISPECTOR, Clarice. Todos os contos. Rio de Janeiro: Rocco, 2016.

MARTIN, Marcel. A linguagem cinematográfica. Tradução: Paulo Neves. São Paulo: Brasiliense, 2003.

NUNES, Benedito. O drama da linguagem: uma leitura de Clarice Lispector. São Paulo: Ática, 1989.

SCLIAR, Moacyr. Saturno nos trópicos: a melancolia europeia chega ao Brasil. São Paulo: Companhia das Letras 2003.

STAROBINSKI, Jean. A tinta da melancolia: uma história cultural da tristeza. Tradução: Rosa Freire d'Aguiar. São Paulo: Companhia das Letras, 2016. 